\title{
Women's knowledge on the menopausal transition in relation to their socio-economic status
}

\author{
Monika Krzyżanowska, Katarzyna Górecka \\ Department of Human Biology, University of Wroclaw, Poland
}

\begin{abstract}
Current reports indicate that there is a relationship between women's socio-economic status (SES) and their level of knowledge on the menopausal transition. The aim of the study was to assess the level of knowledge in pre-menopausal women on the most frequent symptoms accompanying the menopausal transition as well as conventional and nonconventional therapies of alleviating symptoms in relation to women's SES. The study was conducted among 114 women with the mean age of about $44( \pm 2.51)$ years. A self-prepared questionnaire was used to investigate their SES and level of knowledge on the most common menopausal symptoms and methods of alleviating them. Most of the women (66.7\%) were familiar with the most frequent menopausal symptoms. The women associated menopause with hot flashes (41.2\%), mood swings (27.2\%) and depression (15.8\%). The majority of the women (84.2\%) were familiar with hormone replacement therapy (HRT) and $43 \%$ of them were familiar with alternative therapies (AT). Better-educated women were more likely to take AT in the future while less-educated women intended to take HRT. Place of residence and income did not differentiate whether women intended to use HRT or AT during the menopausal transition. There was no difference in the level of women's knowledge on HRT in relation to SES. There was an association between the level of knowledge on AT and education as well as place of residence. Better-educated women from medium and large urban centres tended to know unconventional methods of alleviating climacteric symptoms. Education was the most significant predictor of self-assessed level of knowledge on the menopausal transition.
\end{abstract}

Key words: knowledge, menopausal symptoms, conventional and alternative therapies, socio-economic status.

\section{Introduction}

Menopause defines the moment when menstrual bleeding ceases to occur due to changes in the hormone system. There are three consecutive periods related to menopause: premenopause, perimenopause and postmenopause. The first period is defined as the stage before the last menstrual period in which the irregularity of menstruation is increased and falls in the age range of about 45-49 years. Perimenopause commences with the onset of changes to the menstrual cycle, when the first clinical, biological, endocrine and psychoemotional features of the approaching last menstrual period begin to appear, as well as one to two years after menopause [1]. Postmenopause is defined by the $\mathrm{WHO}$ as the period of life after the last menstrual period, regardless of whether menopause is natural or artificially induced [2]. The gradual or sudden cessation of oestradiol and progesterone production by the ovaries is manifested by diverse vasomotor, psychological, somatic and atrophic changes, which are expressed with very unique symptoms known as climacteric. The menopause in Polish women occurs on average at age 51, but the first menopausal symptoms have already taken place in the climacteric period [3]. Occurrence and growth of ailments in the period can considerably affect the women's quality of life; therefore it is important to introduce effective methods aimed at alleviating uncomfortable symptoms. Available therapies include conventional and alternative ones. The basis for selecting a suitable therapy to alleviate menopausal symptoms is proper education, obtained from reliable sources as well as from gynaecological clinics. Current reports indicate that there is a relationship between women's socio-economic (SES) status (education level, place of residence and professional activity) and their level of knowledge on the menopausal transition. Currently, the knowledge level of Polish women [4-7] on hormone replacement therapy (HRT), the most frequent menopausal symptoms and the issue of menopause in the broad sense is limited.

The aim of the study was to assess the knowledge level in pre-menopausal women on the most frequent symptoms accompanying the menopausal transition as 
well as conventional and nonconventional therapies of alleviating symptoms in relation to women's SES.

\section{Material and methods}

\section{Material status and method}

Between 2018 and 2019, a total of 465 women aged 40-88 years were invited to participate in the study. At recruitment, all women completed a detailed questionnaire collecting information on their reproductive factors, SES (place of residence, education level, occupational status and net income per person/per month in the family) as well as their menopausal status. In addition, all women at climacteric or postmenopausal periods answered questions covered experienced menopausal symptoms and conventional (HRT) or alternative therapies (AT) of alleviating them, whereas premenopausal women were asked about their level of knowledge on the menopausal transition and conventional or alternative therapies. Natural menopause was defined according to the World Health Organization as amenorrhoea for at least 12 consecutive months without other obvious reasons. All women who experienced a surgical menopause (i.e. hysterectomy and/or unilateral or bilateral ovariectomy) were excluded. A total of 351 women were at climacteric or postmenopausal periods at the time of enrolment and were therefore excluded. Finally, 114 premenopausal women were included in the study and fully completed the questionnaires, especially data on their last menstruation, state of knowledge on menopause and therapies for alleviating menopausal symptoms. All of the women in the final sample menstruated regularly and did not have any occurrence of menopausal ailments either at the time of the examination or in the past. Moreover, all participants were fully informed about the purpose of the study, its anonymity, and the possibility of refusing to participate in the study, and gave their consent.

Place of residence was categorized as 1) rural and small urban centre with a population under 50,000, 2) medium-size urban centre with a population between 50,000 and 500,000 and 3) large urban centre with a population over 500,000. Women's education level was classified as 1) low-level (no education, primary or vocational school education), 2) mid-level (secondary, post-secondary school) and 3) high-level (completed MA studies, continuation of education after university studies - postgraduate studies, second line of studies, doctoral studies, etc.). Occupational status was categorized as 1) active and 2) inactive. Net income per person/per month in the family was described as 1) low (< 1000 PLN/pers.), 2) medium (1000-2000 PLN/ pers.) or 3) high ( 2000 PLN/pers.).

Five questions were used to assess the women's knowledge on climacteric symptoms, HRT and AT: 'Do you know climacteric symptoms that occur during the menopausal transition? If 'yes', please tick them on the list below'; 'Do you know what the term HRT (hormone replacement therapy) means?': 'yes - I am familiar with the term HRT', no - I am not familiar with the term HRT'; 'Do you know what the term AT (alternative therapies) means?': 'yes - I am familiar with the term AT', 'no - I am not familiar with the term AT'. Also a seven-item Likert scale was designed to evaluate self-assessed level of knowledge on the menopausal transition. In addition, the women also stated whether they were going to undergo HRT or other (alternative therapies) aimed at alleviating climacteric symptoms.

\section{Ethical considerations}

All procedures contributing to this work complied with the ethical standards of the relevant national and institutional committees on human experimentation and with the Helsinki Declaration of 1975, as revised in 2008.

\section{Statistical analysis}

Characteristics of the sample were described using means and standard deviation values for normally distributed continuous variables as well as frequencies and percentages for categorical variables. In the univariate analysis the $\chi^{2}$ test and two-tailed independent sample Student's t-test were used. Moreover, two types of regression analyses were undertaken. The first was a simple regression that examined the effects of a single variable, e.g. place of residence, in relation to the level of knowledge on the menopausal transition. In the second analysis a stepwise multiple regression procedure was used in which the most significant predictor entered the model first followed by the second most significant predictor, and so on. STATISTICA version 13.0 for Windows software was used to analyse the data.

\section{Results}

The average age of the women was $44.14 \pm 2.51$ years. Overall $53.5 \%$ of women came from medium-size or large urban centres, $47.4 \%$ had a high level of education, $75.4 \%$ were occupationally active and $38.6 \%$ had a medium or high income level. The distribution of socio-economic variables is presented in Table 1.

Most of the women (66.7\%) stated that they were familiar with the most frequent menopausal symptoms. The women associated menopause mainly with hot flashes (41.2\%), mood swings (27.2\%) and depression (15.8\%). The least frequently mentioned symptoms were sexual dysfunctions (0.9\%), body swellings (0.9\%), intestinal and gastric disorders (0.9\%) and lowered physical fitness (0.9\%) (Table 2). 
Table 1. Distribution of socio-economic variables of pre-menopausal women $(\mathrm{n}=114)$

\begin{tabular}{lll}
\hline Variables & $\boldsymbol{N}$ & $\%$ \\
\hline Place of residence & & \\
\hline Rural and small urban centre & 53 & 46.5 \\
\hline Medium-size urban centre & 35 & 30.7 \\
\hline Large urban centre & 26 & 22.8 \\
\hline Education level & & \\
\hline Low & 18 & 15.8 \\
\hline Medium & 42 & 36.8 \\
\hline High & 54 & 47.4 \\
\hline Occupational status & & \\
\hline Inactive & 28 & 24.6 \\
\hline Active & 86 & 75.4 \\
\hline Income/person/month & & \\
\hline$<1000$ PLN & 26 & 22.8 \\
\hline $1000-2000$ PLN & 44 & 38.6 \\
\hline$>2000$ PLN & 44 & 38.6 \\
\hline
\end{tabular}

The majority of the women (84.2\%) were familiar with term HRT and $43 \%$ of the respondents were familiar with AT as well (Table 3).

Altogether $60.5 \%$ of the women declared willingness to take HRT in the future while $27.2 \%$ did not plan to use such therapy and only $12.3 \%$ stated that they were going to use AT (Table 4).

It appeared that better-educated women were more likely to take AT to alleviate climacteric symptoms in the future or not to take any kind of therapies while less-educated women reported taking HRT $\left(\chi^{2}=7.570\right.$, $\mathrm{df}=2, p=0.023)$. Place of residence $\left(\chi^{2}=0.120, \mathrm{df}=2\right.$, $p=0.942)$ and income $\left(\chi^{2}=5.356, \mathrm{df}=2, p=0.069\right) \mathrm{did}$ not differentiate whether women intended to use HRT or AT during the menopausal transition.

There was no significant differences in women's level of knowledge on HRT in relation to SES $\left(\chi^{2}=3.596\right.$, $\mathrm{df}=2, p=0.166$ - place of residence; $\chi^{2}=0.670, \mathrm{df}=2$, $p=0.715$ - education level; $\chi^{2}=2.713, \mathrm{df}=2, p=0.258$ - income/person/month). There was an association between the level of knowledge on AT and education $\left(\chi^{2}=12.260, \mathrm{df}=2, p=0.002\right)$ as well as place of residence $\left(\chi^{2}=8.971, \mathrm{df}=2, p=0.011\right)$ (Table 5). Better-educated women from medium and large urban centres tended to know nonconventional methods of alleviating climacteric symptoms including applying herbs and herbal mixes (27.6\%), following proper dietary habits (20.7\%), maintaining physical activity (20.7\%), acupuncture (13.8\%) and aromatherapy (10.3\%). Using supplements was the least commonly mentioned item (6.9\%) (not presented).

The results (Table 6) revealed that the most significant predictor of self-assessed level of knowledge on the menopausal transition was education. Before and after
Table 2. Women's knowledge on climacteric symptoms that occur during menopausal transition

\begin{tabular}{|c|c|c|}
\hline & $N$ & $\%$ \\
\hline \multicolumn{3}{|l|}{ Disorders of menstruation cycle } \\
\hline Menstruation disorders & 10 & 8.8 \\
\hline Absence of menstruation & 8 & 7.0 \\
\hline Total & 18 & 15.8 \\
\hline \multicolumn{3}{|l|}{ Vasomotor symptoms } \\
\hline Hot flashes & 47 & 41.2 \\
\hline Excessive perspiration & 16 & 14.0 \\
\hline Night sweats & 12 & 10.5 \\
\hline Total & 75 & 65.7 \\
\hline \multicolumn{3}{|l|}{ Mental symptoms } \\
\hline Mood swings & 31 & 27.2 \\
\hline Depression & 18 & 15.8 \\
\hline Sleep disorders & 15 & 13.2 \\
\hline Fatigue & 7 & 6.1 \\
\hline Irritability & 6 & 5.3 \\
\hline Nervousness & 5 & 4.4 \\
\hline Anxiety & 3 & 2.6 \\
\hline Sleeplessness & 2 & 1.8 \\
\hline Total & 87 & 76.4 \\
\hline \multicolumn{3}{|l|}{ Somatic symptoms } \\
\hline Muscle and joint pains & 16 & 14.0 \\
\hline Headaches & 4 & 3.5 \\
\hline Urinary incontinence & 3 & 2.6 \\
\hline Heart palpitations & 2 & 1.8 \\
\hline Dizziness & 2 & 1.8 \\
\hline Body swellings & 1 & 0.9 \\
\hline Intestinal and gastric disorders & 1 & 0.9 \\
\hline Total & 29 & 25.5 \\
\hline \multicolumn{3}{|l|}{ Symptoms connected with sexual activity } \\
\hline Vaginal dryness/itching & 6 & 5.3 \\
\hline Lowered libido & 2 & 1.8 \\
\hline Sexual dysfunctions & 1 & 0.9 \\
\hline Total & 9 & 8.0 \\
\hline \multicolumn{3}{|l|}{ Other mentioned symptoms } \\
\hline Problems with maintaining proper body weight & 13 & 11.4 \\
\hline Osteoporosis & 2 & 1.8 \\
\hline Increased risk of tumours & 2 & 1.8 \\
\hline Blood pressure fluctuations & 2 & 1.8 \\
\hline Lowered physical fitness & 1 & 0.9 \\
\hline Total & 20 & 17.7 \\
\hline
\end{tabular}

the stepwise multiple regression analysis, better-educated women tended to have a higher level of knowledge on the menopausal transition, on average, than less-educated women ( $p=0.007$ and $p=0.003$, respectively). Net income per person/per month in the family differ- 
Table 3. Women's knowledge on hormone replacement therapy and alternative therapies

\begin{tabular}{lll}
\hline & $\boldsymbol{N}$ & $\%$ \\
\hline HRT & & \\
\hline Familiar with the term HRT & 96 & 84.2 \\
\hline Not familiar with the term HRT & 18 & 15.8 \\
\hline AT & 49 & 43.0 \\
\hline Familiar with the term AT & 65 & 57.0 \\
\hline Not familiar with the term AT &
\end{tabular}

Table 5. Results of the level of knowledge on alternative therapies in relation to socio-economic factors

\begin{tabular}{|c|c|c|c|c|}
\hline \multirow[t]{3}{*}{ Variables } & \multicolumn{2}{|c|}{$\begin{array}{c}\text { Level } \\
\text { of knowledge } \\
\text { on AT }\end{array}$} & \multirow[t]{3}{*}{$\chi^{2}$} & \multirow[t]{3}{*}{$p$} \\
\hline & No & Yes & & \\
\hline & $\%$ & $\%$ & & \\
\hline \multicolumn{5}{|l|}{ Place of residence } \\
\hline Rural and small urban centre & 56.92 & 32.65 & \multirow{3}{*}{8.971} & \multirow{3}{*}{0.011} \\
\hline Medium-size urban centre & 29.23 & 32.65 & & \\
\hline Large urban centre & 13.85 & 34.70 & & \\
\hline \multicolumn{5}{|l|}{ Education level } \\
\hline Low & 16.92 & 14.29 & \multirow{3}{*}{12.260} & \multirow{3}{*}{0.002} \\
\hline Medium & 49.23 & 20.41 & & \\
\hline High & 33.85 & 65.31 & & \\
\hline \multicolumn{5}{|l|}{ Income/person/month } \\
\hline$<1000$ PLN & 24.62 & 20.41 & \multirow{3}{*}{1.440} & \multirow{3}{*}{0.487} \\
\hline 1000-2000 PLN & 41.54 & 34.69 & & \\
\hline$>2000$ PLN & 33.85 & 44.90 & & \\
\hline
\end{tabular}

Table 4. Women's stated intentions of taking hormone replacement therapy or alternative therapies in the future

\begin{tabular}{lrc}
\hline $\begin{array}{l}\text { 'Are you going to take HRT or AT during } \\
\text { the menopausal transition?' }\end{array}$ & $\boldsymbol{N}$ & $\%$ \\
\hline 'No, I am not going to take any kind of therapies' & 31 & 27.2 \\
\hline 'I am going to take HRT' & 69 & 60.5 \\
\hline 'I am going to take AT' & 14 & 12.3 \\
\hline HRT - hormone replacement therapy, AT - alternative therapies &
\end{tabular}

entiated the level of knowledge on the menopausal transition only before the stepwise multiple regression analysis - women from high income families tended to have a higher knowledge level. Before and after the stepwise multiple regression analysis there was no relationship between self-assessed level of knowledge on the menopausal transition and place of residence ( $p=0.067$ and $p=0.304$, respectively) (Table 6).

\section{Discussion}

Knowledge about the menopausal transition and various uncomfortable menopausal symptoms is helpful to adapt to this stage of life as well as to improve women's quality of life. Having the right information about menopause can help women to make better choices between treatment options for menopausal symptoms. Available therapies include conventional and alternative ones. The basis for selecting a suitable therapy to alleviate menopausal symptoms is proper education obtained from reliable sources as well as from gynaecological clinics, regardless of women's socio-economic background. Current literature reports that the knowledge level of Polish women [4-7] on HRT, the most frequent menopausal symptoms and

Table 6. Results of simple (unadjusted) and stepwise (adjusted) multiple regression analyses to predict self-assessed level of knowledge on menopausal transition

\begin{tabular}{|c|c|c|c|c|c|c|c|}
\hline \multirow[t]{2}{*}{ Variables } & \multicolumn{4}{|c|}{ Simple } & \multicolumn{3}{|c|}{ Stepwise } \\
\hline & $n$ & Mean & $p$ & $R^{2}$ & Mean & $p$ & Adj. $R^{2}$ \\
\hline Education level & & & & & Step 1 & \multirow{4}{*}{0.003} & 0.082 \\
\hline Low & 18 & -1.01 & 0.007 & 0.084 & -0.36 & & \\
\hline Medium & 42 & -0.66 & & & -0.02 & & \\
\hline High & 54 & 4.57 & & & 0 & & \\
\hline Income/person/month & & & & & Step 2 & \multirow{4}{*}{0.118} & \\
\hline$<1000$ PLN & 26 & -0.78 & 0.032 & 0.060 & -0.09 & & \\
\hline 1000-2000 PLN & 44 & -0.64 & & & -0.18 & & \\
\hline$>2000$ PLN & 44 & 4.59 & & & 0 & & \\
\hline Place of residence & & & & & Step 3 & \multirow{4}{*}{0.304} & \\
\hline Rural and small urban centre & 53 & -0.75 & 0.067 & 0.048 & -0.22 & & \\
\hline Medium-size urban centre & 35 & -0.33 & & & -0.05 & & \\
\hline Large urban centre & 26 & 4.62 & & & 0 & & \\
\hline
\end{tabular}


the issue of menopause in the broad sense is unfortunately limited. What is more, no studies were found on women's knowledge about AT for alleviating menopausal symptoms in relation to their SES. This is why this study was undertaken to examine the knowledge level in pre-menopausal women on the most frequent symptoms accompanying the menopausal transition as well as conventional and nonconventional therapies of alleviating symptoms in relation to women's SES based not only on their education level but also place of residence, income and occupational status.

The main findings generally indicated that the most significant predictor of self-assessed level of knowledge on the menopausal transition was education, with better-educated women tending to have a higher knowledge level, on average, than less-educated women. Educational variation in level of knowledge on menopause has been widely reported in many countries. A study of 320 women (teachers, nurses, office workers and women with basic education) living in the cities of York (UK), Łódź (Poland) and Ternopil (Ukraine) found that women's educational level had a major influence on their knowledge about the term of menopause, its symptoms, understanding the deficiency of female hormones, and usage of HRT [7]. In a survey of 770 Andalusian women, aged 30-60 years, middle/high educational background explained the largest amount of the variability in knowledge of menopause [8]. In an Italian survey of 720 women, aged 45-60 years, lack of knowledge of menopause was associated with women's low educational level [9]. Data from mid life Taiwanese women's knowledge of perimenopause indicated that only education was significantly associated with perimenopause knowledge level [10]. The study of Noroozi et al. showed that among 40-45-year-old women from Iran there was a meaningful relation between women's knowledge, so that higher educated, employed and satisfied women had higher knowledge of menopause [11]. Data from Brazilian women, aged 45-60 years, confirmed that higher education level was significantly associated with a higher knowledge on menopause [12]. A study of 44 Turkish women (with a mean age of 50.41 \pm 6.36 years) living in the district centre of Beylikova and having mostly a lower educational level showed positive changes in menopause-related level of knowledge after a planned training programme [13]. Similar results were seen in Eritrean women, where the structured educational intervention was beneficial to the women in improving their knowledge of and attitude toward menopause [14]. Another study conducted on 497 Emirati women, aged 30-64 years, indicated that illiterate women had the lowest knowledge on menopause, menopausal hormone therapy and associated health risks whereas university graduates had the highest. Also, employed women had higher menopause-related knowledge than unemployed women [15].
A number of studies have confirmed an association between education level and HRT-related knowledge, with lower or lack of knowledge being the greatest in the less educated women [16-20]. Previous research carried out on a nationally representative sample (HORTPOL 2002) of 1544 Polish women between 18 and 87 years showed that women with primary education were less likely to use HRT than those with a medium or higher education level. What is more, $63 \%$ of premenopausal women, aged 35-44 years, had heard of HRT [4]. Similar results were obtained by Bińkowska et al. in a sample of 1083 Polish women aged 45-54 years where self-assessed knowledge on HRT increased with education level. What is more, $35 \%$ of women did not know anything about HRT and $48 \%$ did not know the most frequent menopausal symptoms. In addition, the majority of women (96\%) who were familiar with HRT opted for this therapy, but $15 \%$ of them limited its use only to exceptional situations [5]. Other studies (SOPKARD and GDYNIAKARD) conducted on a sample of 586 Polish women, aged 50 years (269 postmenopausal and 317 premenopausal), indicated that in general $80 \%$ of women had heard of HRT and it was differentiated by educational level: $93.5 \%$ among better-educated women and $56.4 \%$ among the less educated [6]. By contrast, a survey conducted in the North East of Scotland on 600 women, aged 20-69 years, reported a more pronounced increase in ever use of HRT in the less educated women (increase of $24 \%$ since 1991) compared with the more educated (increase of 13\%) [21]. In the current study, $84.2 \%$ of the women were familiar with the term HRT and $43 \%$ were familiar with alternative therapies. Moreover, the prevalence of declared willingness to take HRT in the future was $60.5 \%$, whereas taking AT was reported by only $12.3 \%$ of the women. However, better-educated women from medium and large urban centres tended to know nonconventional methods of alleviating climacteric symptoms and were more likely to take AT in the future or not to take any kind of therapies. Interestingly, there was no significant differences in women's level of knowledge on HRT in relation to SES.

Nonconventional methods of alleviating menopausal symptoms are particularly used by women who cannot use HRT. There is evidence on the beneficial influences of applying herbs [22-27], a properly balanced diet [28-30] and regular physical activity [31-34] in order for women of menopausal age to maintain health and vitality. Bahri et al. studied 473 women, aged 45-60 years, and found out that the most efficient alternative way of alleviating menopausal symptoms was herbalism, applied by $33 \%$ of the participants. Physical activity was preferred by $3.5 \%$ of the women and $2.9 \%$ had changed their diet [35]. Another study on a sample of 88,430 British women, aged $50-74$ years, demonstrated that $25.1 \%$ of them had used at least one alternative 
method during the menopausal transition, and $43.8 \%$ chose herbal therapy. Furthermore, $42.6 \%$ of the women used vitamins, $32.1 \%$ of them took into consideration the significance of an individual approach to life and $21.6 \%$ applied phytoestrogens in order to decrease tiredness due to menopausal symptoms [36]. The results of the present research confirmed that the women correctly recognised the most common nonconventional menopausal therapies and selected applying herbs (27.6\%) and introducing proper dietary habits (20.6\%), whereas using supplements was the least commonly mentioned item (6.9\%).

The present study indicated that women associated menopausal symptoms most commonly with hot flashes $(41.2 \%)$ followed by mood swings $(27.2 \%)$, depression (15.8\%) and excessive perspiration (14.0\%). Similar results were presented by Bińkowska et al. [5] as well as Wyderka and Zdziennicki [37]. Beck et al. also observed that among British women hot flashes were the most commonly mentioned menopausal symptoms together with fatigue, night sweats and sleeplessness [38], which dominate the list of the most common menopausal ailments [39-42].

To summarize, the current study revealed that premenopausal women's knowledge on the most commonly occurring menopausal ailments and methods of alleviating them depends on their education level. Most of the women stated that they were familiar with the most frequent menopausal symptoms. Furthermore, the women were familiar with the term 'HRT' and most of them declared willingness to take HRT in the future. What is more, the HRT-related knowledge was not differentiated by women's SES. Generally, the most common nonconventional menopausal therapies were correctly recognised. However, better-educated women from medium and large urban centres tended to know nonconventional methods of alleviating climacteric symptoms and were more likely to take AT in the future or not to take any kind of therapies than the less-educated women from rural and small urban centres.

\section{Limitations}

The current study has also some limitations. First, our survey findings were based on a small sample. Second, we lacked information on the level of detailed knowledge on positive and negative effects of using HRT. The collected data were based on a self-reported questionnaire and women's answers.

\section{Conclusions}

We conclude that the knowledge level about menopausal symptoms and ways of coping with them are critical for women to access health care in the menopausal period. More and qualified information should be provided to support women in making informed choices in relation to menopause and the use of systemic HRT or AT. Women need to be well informed about health issues so that they can have a say in health-care decisions concerning themselves and the protection of their health, regardless of their socio-economic background.

\section{Disclosure}

The authors report no conflict of interest.

\section{References}

1. Naworska B, Brzęk A, Bąk-Sosnowska M. The relationship between health status and social activity of perimenopausal and postmenopausal women (health status and social relationships in menopause). Int J Environ Res Public Health 2020; 17: 8388.

2. World Health Organization. Research on the menopause in the 1990s. In: WHO Technical Report Series 866; Report of a WHO Scientific Group; WHO: Switzerland, Geneva 1996.

3. Kaczmarek M. Określenie wieku menopauzy naturalnej w populacji kobiet polskich. Menopause Rev 2007; 2: 77-82.

4. 4. Rachoń D, Zdrojewski T, Suchecka-Rachoń K, et al. Knowledge and use of hormone replacement therapy among Polish women: estimates from a nationally representative study - HORTPOL 2002. Maturitas 2004; 47 31-37.

5. Bińkowska M, Pietrzak B, Dębski R. Hormonalna terapia zastępcza w grupie kobiet polskich w wieku 45-54 lat. Wiedza, opinie, stosowanie. Menopause Rev 2005; 2: 19-27.

6. Mogilnaya I, Rachoń D, Zdrojewski T, et al. Ocena wiedzy na temat hormonalnej terapii zastępczej oraz jej częstość stosowania wśród 50-letnich mieszkanek Gdyni i Sopotu. Wyniki badania SOPKARD i GDYNIAKARD. Menopause Rev 2005; 9: 28.

7. Wyderka M, Zdziennicki A, Byalek T. Poziom wiedzy wybranych grup kobiet na temat okresu przekwitania. Menopause Rev 2007; 6: 365-370.

8. Padilla GFM, Santos LV, Gómez TAM, et al. Valoración de conocimientos sobre el climaterio en mujeres andaluzas [Evaluation of knowledge about climacteric in Andalusian women]. Aten Primaria 2000; 26 : 476-481.

9. Donati S, Cotichini R, Mosconi P, et al. Menopause: knowledge, attitude and practice among Italian women. Maturitas 2009; 63: 246-252.

10. Tsao LI, Chang WY, Hung LL, et al. Perimenopausal knowledge of mid-life women in northern Taiwan. J Clin Nurs 2004; 13: 627-635.

11. Noroozi E, Dolatabadi NK, Eslami AA, et al. Knowledge and attitude toward menopause phenomenon among women aged 40-45 years. J Educ Health Promot 2013; 2: 25

12. De Arruda Amaral I, Baccaro L, Lui-Filho J, et al. Factors associated with knowledge about menopause and hormone therapy in middle-aged Brazilian women. Menopause 2018; 25: 803-810.

13. Koyuncu T, Unsal A, Arslantas D. Evaluation of the effectiveness of health education on menopause symptoms and knowledge and attitude in terms of menopause. J Epidemiol Glob Health 2018; 8: 8-12.

14. Gebretatyos H, Ghirmai L, Amanuel S, et al. Effect of health education on knowledge and attitude of menopause among middle-age teachers. BMC Womens Health 2020; 20: 232.

15. Smail L, Jassim GA, Sharaf KI. Emirati women's knowledge about the menopause and menopausal hormone therapy. Int J Environ Res Public Health 2020; 17: 4875.

16. Sinclair HK, Bond CM, Taylor RJ. Hormone replacement therapy: a study of women's knowledge and attitudes. Br J Gen Pract 1993; 43: 365-370.

17. France K, Lee C, Schofield M. Hormone replacement therapy: knowledge, attitudes, and well-being among middle-aged Australian women. Int J Behav Med 1996; 3: 202-220.

18. Schneider HP. Cross-national study of women's use of hormone replacement therapy (HRT) in Europe. Int J Fertil Womens Med 1997; 42: 365-375. 
19. Søgaard AJ, Tollan A, Berntsen GK, et al. Hormone replacement therapy: knowledge, attitudes, self-reported use and sales figures in Nordic women. Maturitas 2000; 35: 201-214.

20. Pacello P, Baccaro Luiz F, Pedro AO, et al. Prevalence of hormone therapy, factors associated with its use, and knowledge about menopause: a population-based household survey. Menopause 2018; 25: 683-690.

21. Lewin KJ, Sinclair HK, Bond CM. Women's knowledge of and attitudes towards hormone replacement therapy. Fam Pract 2003; 20: 112-119.

22. Geller SE, Studee L. Contemporary alternatives to plant estrogens for menopause. Maturitas 2006; 55: S3-S13.

23. Geller SE, Studee L. Botanical and dietary supplements for mood and anxiety in menopausal women. Menopause 2007; 14: 541-549.

24. Laakmann E, Grajecki D, Doege K, et al. Efficacy of Cimicifuga racemosa, Hypericum perforatum and Agnus castus in the treatment of climacteric complaints: a systematic review. Gynecol. Endocrinol 2012; 28: 703-709.

25. Taylor M. Complementary and alternative approaches to menopause. Endocrinol Metab Clin N Am 2015; 44: 619-648.

26. Ghazanfarpour M, Sadeghi R, Latifnejad Roudsari R, et al. Effects of flaxseed and Hypericum perforatum on hot flash, vaginal atrophy and estrogen-dependent cancers in menopausal women: a systematic review and meta-analysis. Avicenna J Phytomed 2016; 6: 273-283.

27. Kanadys W, Barańska A, Jędrych M, et al. Effects of red clover (Trifolium pratense) isoflavones on the lipid profile of perimenopausal and postmenopausal women - a systematic review and meta-analysis. Maturitas 2020; 132: 7-16.

28. Cheng G, Wilczek B, Warner M, et al. Isoflavone treatment for acute menopausal symptoms. Menopause 2007; 14: 468-473.

29. Borrelli F, Ernst E. Alternative and complementary therapies for the menopause. Maturitas 2010; 66: 333-343.

30. Lupsa BC, Insogna K. Bone health and osteoporosis. Endocrinol Metab Clin N Am 2015; 44: 517-530.

31. Stojanovska L, Apostolopoulos V, Polman R, et al. To exercise, or, not to exercise, during menopause and beyond. Maturitas 2014; 77: 318-323.

32. Grindler N, Santoro N. Menopause and exercise. Menopause 2015; 22: 1351-1358.

33. Bailey TG, Cable NT, Aziz N, et al. Exercise training reduces the frequency of menopausal hot flushes by improving thermoregulatory control. Menopause 2016; 23: 708-718

34. Witkowski S, Serviente C. Endothelial dysfunction and menopause: is exercise an effective countermeasure? Climacteric 2018; 21: 267-275.

35. Bahri N, Sajjadi M, Sadeghmoghadam L. The relationship between management strategies for menopausal symptoms and women's decision making styles during menopausal transition. Menopause Rev 2019; 18: 174-179.

36. Gentry-Maharaj A, Karpinskyj C, Glazer C, et al. Prevalence and predic tors of complementary and alternative medicine/non-pharmacological interventions use for menopausal symptoms within the UK Collaborative Trial of Ovarian Cancer Screening. Climacteric 2017; 20: 240-247.

37. Wyderka M, Zdziennicki A. Poziom wiedzy wybranych grup mieszkanek Łodzi na temat okresu przekwitania. Menopause Rev 2006; 5: 317-322.

38. Beck V, Brewis J, Davies A. The remains of the taboo: experiences, at titudes, and knowledge about menopause in the workplace. Climacteric 2019; 23: 158-164.

39. Moilanen J, Aalto AM, Hemminki E, et al. Prevalence of menopause symptoms and their association with lifestyle among Finnish middleaged women. Maturitas 2010; 67: 368-374.

40. Depypere H, Pintiaux A, Desreux J, et al. Coping with menopausal symptoms: an internet survey of Belgian postmenopausal women. Maturitas 2016; 90: 24-30.

41. Stuenkel C. Vasomotor and related menopause symptoms. Clin Obstet Gynecol 2018; 61: 433-446.

42. Augoulea A, Moros M, Lykeridou A, et al. Psychosomatic and vasomotor symptom changes during transition to menopause. Menopause Rev 2019; 18: 110-115. 